Table 2. Variables predictive of a DAS 28 remission at 6 months for IV bDMARDs

\begin{tabular}{|c|c|c|c|c|}
\hline \multirow[t]{2}{*}{ Biomarkers } & \multicolumn{3}{|c|}{$\begin{array}{l}\text { Univariate } \\
\text { Analysis }\end{array}$} & \multirow{2}{*}{$\begin{array}{c}\begin{array}{c}\text { Bivariate Logistic } \\
\text { regression Analysis }\end{array} \\
\text { OR (CI95\%) }\end{array}$} \\
\hline & $\begin{array}{c}\text { DAS } 28 \\
\text { remission } \\
(n=33)\end{array}$ & $\begin{array}{c}\text { No Remission } \\
(n=122)\end{array}$ & $\begin{array}{c}\mathbf{p} \\
\text { value }\end{array}$ & \\
\hline \multicolumn{5}{|l|}{ Clinical data } \\
\hline $\begin{array}{l}\mathrm{Nb} \text { of sequence }>1 \\
\text { Radiography }(\mathrm{n}=110)\end{array}$ & 19 (57.6\%) & 92 (75.4\%) & 0.052 & $0.4(0.2-1.0)$ \\
\hline $\begin{array}{l}\text { Erosive RA } \\
\text { US }(n=127)\end{array}$ & $22(88.0 \%)$ & $61(71.8 \%)$ & 0.118 & $0.3(0.1-1.3)$ \\
\hline Erosive RA & $28(96.6 \%)$ & 82 (83.7\%) & 0.117 & $0.2(0.0-1.4)$ \\
\hline $\mathrm{Nb} \mathrm{B}$ mode synovitis & $7.7(4.5)$ & $5.5(3.9)$ & 0.013 & $0.9(0.8-1.0)$ \\
\hline Nb PD+ synovitis & $6.5(5.0)$ & $4.3(3.3)$ & 0.031 & $0.9(0.8-1.0)$ \\
\hline
\end{tabular}

All qualitative variables with a $p$ value $<0.2$ on bivariate analysis were incorporated in the multivariate model (RF +, ACPA +, US erosive RA, Nb B mode synovitis, Nb PD+ synovitis, RX erosive RA). Only patients with all data available were incorporated in the multivariate logistic regression analysis $(n=103 / 155)$. In multivariate analysis only the number of $B$ mode synovitis was still significant with $\mathrm{OR}=1.1(\mathrm{Cl} 95 \%$ : 1.0-1.3) $(\mathrm{p}<0,019)$

Conclusion: In RA patients treated by IV bDMARDs, number of PD+ synovitis on ultrasonography was the only predictive biomarker of DAS 28 remission. Disclosure of Interests: Benjamin Laurent Grant/research support from: BMS, Stephane Giuliani Grant/research support from: BMS, Hella MEZGHANI Employee of: BMS, Isabelle Duprat-Lomon Employee of: BMS, Amandine Luc Grant/research support from: BMS, Marcelo De carvalho Bittencourt Grant/research support from: BMS, Cedric BAUMANN Grant/research support from: BMS, Isabelle CHARY VALCKENAERE: None declared, Damien LOEUILLE: None declared DOI: 10.1136/annrheumdis-2020-eular.2331

\section{SAT0043 SERUM BIOMOLECULES AS POTENTIAL BIOMARKERS OF CLINICAL EFFICACY AND PREDICTORS OF RESPONSE TO BIOLOGIC DISEASE MODIFYING ANTI-RHEUMATIC DRUGS IN RHEUMATOID ARTHRITIS PATIENTS}

M. Luque-Tévar ${ }^{1}$, C. Perez-Sanchez ${ }^{1}$, F. U. Pilar ${ }^{1}$, M. Romero-Gómez ${ }^{1}$, A. M. Patiño-Trives ${ }^{1}$, D. Ruiz ${ }^{1}$, I. Arias de la Rosa ${ }^{1}$, M. D. C. Abalos-Aguilera ${ }^{1}$, R. Ortega Castro ${ }^{1}$, A. Escudero Contreras ${ }^{1}$, C. Rodríguez-Escalera ${ }^{2}$, J. J. Pérez Venegas $^{3}$, M. D. Ruiz Montesinos ${ }^{3}$, C. Dominguez ${ }^{3}$, C. Romero Barco ${ }^{4}$, A. Fernandez-Nebro ${ }^{5}$, N. Mena-Vázquez ${ }^{5}$, J. L. Marenco ${ }^{6}$, J. Uceda $^{6}$, M. D. Toledo-Coello ${ }^{7}$, N. Barbarroja Puerto ${ }^{1}$, M. A. Aguirre ${ }^{1}$, C. Lopez-Pedrera ${ }^{1}$

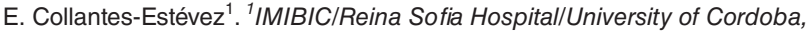
Córdoba, Spain; ${ }^{2}$ University Hospital of Jaen, Jaen, Spain; ${ }^{3}$ Virgen Marcarena Hospital, Sevilla, Spain; ${ }^{4}$ Virgen de la Victoria Hospital, Málaga, Spain; ${ }^{5}$ Regional University Hospital of Malaga, Málaga, Spain; ${ }^{6}$ Virgen de Valme Hospital, Sevilla, Spain; ${ }^{7}$ University Hospital of Jerez de la Frontera, Cádiz, Spain

Objectives: To evaluate the changes promoted in levels of circulating inflammatory mediators in RA patients in response to TNF-a inhibitors (TNFi) and anti-CD20 therapies, in order to identify biomarkers of clinical efficacy and potential predictors of therapeutic response to these drugs.

Methods: In a prospective RA cohort multicenter study, we collected serum from RA patients with moderate or high disease activity prior and after 6 months of treatment with TNFi or rituximab (RTX), and analyzed levels of 27 proteins that constitute a multi-biomarker test of the inflammatory profile of these samples, using a multiplex immunoassay. Patients' response was determined according to the EULAR response criteria (good/moderate/no). We compared basal levels of inflammatory molecules between the differential response patient groups and analyzed their discriminative ability. Logistic prediction models were created to assess the added value of potential inflammatory predictors.

Results: Among 111 total RA patients, 50 of $85(59 \%)$ patients in the TNFi group and 18 of 26 patients in the RTX group (69\%) responded to the biologic treatment. High DAS28 or SDAI scores, or titers of auto-antibodies (RF or ACPA) at baseline were not predictive of response to any treatment. Instead, smoking habit and hyperlipidemia at baseline were predictors of a worse response to any of these bDMARDs. Of the molecules analyzed by the multiplex assay, 14 inflammatory mediators showed a significant downregulation on patients' responders to TNFi therapy. Moreover, the decline on 7 biomolecules was related to reduced DAS28. After RTX treatment, 15 inflammatory mediators were reduced in patients with good clinical response; downregulation in 4 of those biomolecules correlated with reduced DAS28.

In the search for predictors of response to each bDMARD, by using the MetaboAnalyst software, we could classify patients with distinctive therapeutic response based on the baseline levels of the inflammatory molecules analyzed. Receiver operating characteristic (ROC) analyses for those multiple biomarkers allowed us to further identify specific signatures of inflammatory biomolecules that may serve as predictors of response to each bDMARD therapy with high sensitivity and specificity. Thus, a signature of five molecules was identified as potential predictor of TNFi response [Vascular endothelial growth factor (VEGF), Eotaxin RANTES, IL7 and IL-17]. Indeed, a signature including three highly expressed cytokines/chemokines in RA serum were identified as predictors of RTX response [interferon-inducible protein 10 (IP10), Eotaxin and monocyte chemotactic protein 1 (MCP-1)].

Conclusion: The extensive analysis of serum inflammatory profile allowed to identify specific and distinctive signatures of biomolecules that, in coordination with known clinical and serological profiles, might predict the response of RA patients to TNFi or RTX treatments.

Acknowledgments : Funded by Junta de Andalucía (PI-0285-2017), ISCIII, (PI18/00837 and RIER RD16/0012/0015) co-funded with FEDER

Disclosure of Interests: María Luque-Tévar: None declared, Carlos PerezSanchez: None declared, Font Ugalde Pilar: None declared, Montserrat Romero-Gómez: None declared, Alejandra M. Patiño-Trives: None declared, Desiree Ruiz: None declared, Iván Arias de la Rosa: None declared, Maria del Carmen Abalos-Aguilera: None declared, Rafaela Ortega Castro: None declared, Alejandro Escudero Contreras: None declared, Carlos Rodríguez-Escalera Speakers bureau: Lilly, GSK, Novartis and Sanofi, José Javier Pérez Venegas: None declared, María Dolores Ruiz Montesinos: None declared, Carmen Dominguez: None declared, Carmen Romero Barco: None declared, Antonio Fernandez-Nebro: None declared, Natalia Mena-Vázquez: None declared Jose Luis Marenco Speakers bureau: ABbvie, Pfzer, lilly, Julia Uceda: None declared, $\mathrm{M}^{\mathbf{a}}$ Dolores Toledo-Coello: None declared, Nuria Barbarroja Puerto Grant/research support from: ROCHE and Pfizer., Speakers bureau: ROCHE and Celgene., Maria A Aguirre: None declared, Chary Lopez-Pedrera Grant/ research support from: ROCHE and Pfizer., Eduardo Collantes-Estévez Grant/ research support from: ROCHE and Pfizer., Speakers bureau: ROCHE, Lilly, Bristol and Celgene.

DOI: 10.1136/annrheumdis-2020-eular.4442

\section{\begin{tabular}{|l|l}
\hline SAT0044 ADIPOCYTOKINE FLUCTUATES WITH INFLAMMATORY \\
\hline
\end{tabular} MARKERS OR DISEASE ACTIVITY IN PATIENTS WITH RHEUMATOID ARTHRITIS FROM FIVE-YEAR DATA OF TOMORROW STUDY}

K. Mamoto $^{1}$, K. Inui ${ }^{1}$, T. Okano ${ }^{1}$, Y. Sugioka ${ }^{2}$, M. Tada $^{3}$, T. Koike ${ }^{2,4}$,

H. Nakamura'. ${ }^{1}$ Osaka City University Graduate School of Medicine, Department of Orthopaedic Surgery, Osaka, Japan; ${ }^{2}$ Osaka City University Graduate School of Medicine, Center for Senile Degenerative Disorders (CSDD), Osaka, Japan; ${ }^{3}$ Osaka City General Hospital, Department of Orthopaedic Surgery, Osaka, Japan; ${ }^{4}$ Search Institute for Bone and Arthritis Disease (SINBAD), Wakayama, Japan

Background: Leptin and adiponectin have been thought to be adipocytokines that promote or suppress inflammation, respectively.

Objectives: The aim of this study was to investigate the relationship between adipocytokine and inflammatory markers or disease activity in patients with rheumatoid arthritis (RA) by using 5-year data of TOMORROW study which is a cohort study and started from 2010 .

Methods: We evaluated inflammatory markers, disease activity score (DAS)CRP, medication and levels of adipocytokines in 202 patients with RA (mean age 58.6 y; medication with biological agents, 54.9\%) and 202 age- and sex-matched healthy volunteers (controls; mean age, $57.4 \mathrm{y}$ ). We eventually compared leptin or adiponectin concentrations in 183 RA patients and 190 controls from 2010 (BL) to 2015 (5Y) and investigated the relationship between adipocytokines and CRP or DAS in patients by using Spearman correlation analysis.

Results: The levels of leptin and adiponectin in patients were significantly higher than controls at all time points. Adiponectin level of patients significantly increased from $B L$ to $5 Y$ compared to controls (Table 1). In patients, adiponectin showed significant negative correlation with CRP at both of $B L$ and $5 Y(B L: R=-0.174,5 Y: R=$ 0.240; $p<0.05$ ), however, not with DAS at BL and $5 Y$. Leptin positively correlated with $\mathrm{CRP}$ at $5 \mathrm{Y}(\mathrm{R}=0.207 ; \mathrm{p}<0.05)$, but not with $\mathrm{CRP}$ at $\mathrm{BL}$ or $\mathrm{DAS}$ at any time Adiponectin levels at $\mathrm{BL}$ and $5 \mathrm{Y}$ were significantly higher in biologics users at $\mathrm{BL}$ and significantly increased from BL to $5 \mathrm{Y}$ compared to patients without biologics. No association between leptin levels and the use of biologics (Table 2).

Conclusion: The level of adiponectin in RA patients with continuous treatments for 5 years increased, and the trend was more pronounced in biologics users These results might indicate that adiponectin is a cytokine involved in anti-inflammatory effects.

Disclosure of Interests: Kenji Mamoto: None declared, Kentaro Inui Grant/ research support from: Janssen Pharmaceutical K.K., Astellas Pharma Inc. Sanofi K.K., Abbvie GK, Takeda Pharmaceutical Co. Ltd., QOL RD Co. Ltd., Mitsubishi Tanabe Pharma, Ono Pharmaceutical Co. Ltd., Eisai Co.,Ltd., 